\title{
The Relationship between Depressive Symptoms and Modifiable Lifestyle Risk Factors in Office Workers
}

\author{
Youngyun Jin, Changduk Ha, Hyeryun Hong, Hyunsik Kang* \\ College of Sport Science, Sungkyunkwan University, Suwon, Korea
}

Background: This study investigated the relationship between depressive symptoms and physical fitness, obesity indices, and vitamin D status in office workers.

Methods: The subjects were 514 adults with more 30 years of experience as office workers in the city of Seoul. Lifestyle risk factors, obesity indices, physical fitness, and serum vitamin D levels were assessed with a standardized protocol. The Beck Depression Inventory (BDI) was used to assess depression status. Vitamin D status was assessed by measuring serum 25 -hydroxyvitamin $\mathrm{D}$ concentrations. Based on the $\mathrm{BDI}$ scores, participants were classified into no depression (ND, BDI $\leq 9)$, mild depression (MiD, $10 \leq \mathrm{BDI} \leq 15)$, and moderate depression (MoD, $16 \leq \mathrm{BDI} \leq 23$ ) groups.

Results: Compared with the high cardiorespriatory fitness group, the low cardiorespiratory fitness (men $\mathrm{OR}=2.618$, women $\mathrm{OR}=1.596$ ) an middle cardiorespiratory fitness group (men $\mathrm{OR}=1.256$, women $\mathrm{OR}=1.110$ ) had significantly higher odds ratio for having depressive symptoms, even after adjustment for age, hypertension, diabetes, hyperlipidemia, cardiovascular disease, alcohol intake, smoking, body mass index (BMI), percent body fat (\%BF), and waist circumference (WC). Compared with the insufficient or deficient vitamin D group, the sufficient vitamin $D$ group had significantly lower odds ratios for having depressive symptoms (men $\mathrm{OR}=0.121$, women $\mathrm{OR}=0.114$ ), even after adjustment for age, hypertension, diabetes, hyperlipidemia, cardiovascular disease, alcohol intake, smoking, BMI, \%BF, and WC.

Conclusion: Vitamin D supplementation and outdoor activities should be key components of a lifestyle intervention against office workers' depression.

Key words: Depression, Physical fitness, Vitamin D, Obesity, Office work

\author{
Received May 2, 2016 \\ Reviewed May 23, 2016 \\ Accepted June 2, 2016 \\ *Corresponding author \\ Hyunsik Kang \\ (i) \\ http://orcid.org/0000-0002-8611-1873 \\ College of Sport Science, Sungkyunkwan \\ University, 2066 Seobu-ro, Jangan-gu, \\ Suwon 16419, Korea \\ Tel: +82-31-299-6911 \\ Fax: +82-31-299-6929 \\ E-mail: hkang@skku.edu
}

\section{INTRODUCTION}

Office workers, who spend most of their time in an office, are exposed to several health risks, such as inadequate physical activity, irregular diet, and stress from excessive workloads; thus, office workers ultimately are at an increased risk of various diseases, including obesity and metabolic disorders. In particular, office workers are confronted by high levels of stress and health risks due to company dinner outings, frequent alcohol use for stress relief, repetitive and monotonous work, and relationships with colleagues. This highlights the importance of focusing attention and efforts on promoting the health of these workers. Further, most office workers have experienced physical anomalies caused by job stress, including mental lethargy and stress-induced digestive disorders, as well as depressive symptoms and depression. ${ }^{1}$

Depression is one of the most common mental disorders that undermine social function and quality of life ${ }^{2}$, and has been identified to be a cause of increased morbidity and mortality by having adverse effects on physical and health. ${ }^{3}$ The World Health Organization reported that approximately $10-15 \%$ of the general population have experienced at least one episode of depressive symptoms during their lifetime. Similarly, there was a Korean report suggest-

Copyright (C) 2017 Korean Society for the Study of Obesity

(c) This is an Open Access article distributed under the terms of the Creative Commons Attribution Non-Commercial License (http://creativecommons.org/licenses/by-nc/4.0/) which permits unrestricted non-commercial use, distribution, and reproduction in any medium, provided the original work is properly cited. 
ing that approximately $10.3 \%$ of all Korean adults aged 18 or older have experienced depressive symptoms, alluding to the escalated individual and social burden from depression. ${ }^{4}$ Depression is associated with high recurrence ${ }^{5}$, and the interaction among biological $\operatorname{loss}^{6}$, psychosocial factors ${ }^{7}$, and lifestyle risk factors has been implicated in causing it. ${ }^{8}$

Physical inactivity, which is a modifiable lifestyle risk factor, is associated not only with depressive symptoms but also with various chronic diseases. Furthermore, it has widely been associated with metabolic diseases, such as hypertension and diabetes, as well as obesity and reduced physical fitness. ${ }^{9}$ In contrast, several reports have suggested that regular physical activity reduces negative emotions, such as depression and anxiety, and increases positive emotions, such as self-esteem and self-efficacy, by promoting shortterm or long-term psychological stability through enhanced physical fitness and reduced stress, worries, and depression. ${ }^{9}$

Recent studies have suggested that the level of vitamin D, a wellknown lifestyle risk factor, is associated with the development of depression. More specifically, vitamin $\mathrm{D}$, which is obtained via food or exposure to sunlight, 1) has receptors distributed in the area of the brain involved with emotional processing and emotional disorders ${ }^{10}, 2$ ) regulates serotonin synthesis by activating the transcription of the trytophan hydroxylase 2 gene $^{11}$, and 3) alters emotions by activating stress responses by eliciting innate immunity and secreting inflammatory cytokines. ${ }^{12}$ However, some reports have yielded contrasting results. One study reported that provision of vitamin $\mathrm{D}$ did not affect depression ${ }^{13}$, and a meta-analysis of ten cross-sectional studies suggested that a low level of vitamin $\mathrm{D}$ is not associated with increased depressive symptoms. ${ }^{14}$ Such heterogeneity in the literature pertaining to the relation between depressive symptoms and vitamin $\mathrm{D}$ concentrations calls for more consistency in the results.

Meanwhile, much attention has been directed to the association between depression and obesity, a major lifestyle risk factor for physical health. Dixon et al. ${ }^{15}$ reported that body mass index (BMI) and depression are significantly correlated, with a particularly intimate association between increased body weight and depression in young women. Further, Guedes et al. ${ }^{16}$ reported that depressive symptoms increase with increasing body fat percentage, waist circumference, waist-hip-ratio, and BMI in patients with met- abolic disorder. Kim et al. ${ }^{17}$ found that obesity and depression were associated in women in their 20s-30s but not in men. As shown here, some studies suggested that obesity is a risk factor for depressive disorder and depressive symptoms, whereas other studies suggested that no association exists between them. Hence, a multilateral approach is crucial for studies investigating associations with depressive symptoms, and we speculate that physical fitness and level of vitamin D, which are modifiable lifestyle risk factors, are correlated with depressive symptoms. In particular, depressive symptoms in office workers might cause deterioration in their physical and mental health and undermine job performance and quality of work. Nevertheless, most studies in Korea have been limited to a survey of adolescents or the elderly, and only a few have explored the association between depression and physical fitness, vitamin $\mathrm{D}$, and obesity. In this context, we aimed to identify the association between depression and modifiable lifestyle risk factors, such as health-related fitness, vitamin D deficiency, and obesity indices, in office workers.

\section{METHODS}

\section{Participants}

We surveyed the depression, alcohol use, and smoking status and measured obesity indices and serum vitamin $\mathrm{D}$ concentrations of 540 office workers aged 30 or older residing in city of Seoul. After excluding 26 individuals for either providing incomplete responses to the depression survey $(\mathrm{n}=18)$ or opting out from the blood test $(\mathrm{n}=8)$, a total of 514 individuals ( $334 \mathrm{men} / 180$ women) were enrolled in the study. The general characteristics of the participants are shown in Table 1 . This study was approved by the Institutional Review Board (IRB) at the Sungkyunkwan University (SKKUIRB-2015-09-001-002). The participants were provided with the detailed information regarding the study and signed on a written informed consent form prior to their participation in the study.

\section{Measurement instruments and methods}

All dependent variables were measured with the participants wearing comfortable clothing after a 12 -hour fast by examiners who were trained in standardized height and weight measurement methods. For the blood test, a venous blood sample was taken 
Table 1. General characteristics of the participants

\begin{tabular}{|c|c|c|c|c|c|c|c|c|}
\hline \multirow{2}{*}{ Variables } & \multicolumn{4}{|c|}{$\operatorname{Men}(n=334)$} & \multicolumn{4}{|c|}{ Women $(n=180)$} \\
\hline & $\begin{array}{c}N D \\
(n=241)\end{array}$ & $\begin{array}{c}\mathrm{MiD} \\
(\mathrm{n}=81)\end{array}$ & $\begin{array}{c}M o D \\
(n=12)\end{array}$ & $\begin{array}{c}P \text { value } \\
\chi^{2}\end{array}$ & $\begin{array}{c}N D \\
(n=94)\end{array}$ & $\begin{array}{c}\text { MiD } \\
(n=71)\end{array}$ & $\begin{array}{c}M o D \\
(n=15)\end{array}$ & $\begin{array}{c}P \text { value } \\
\chi^{2}\end{array}$ \\
\hline Age (year), mean & 45.6 & 48.1 & 51.7 & 0.093 & 42.1 & 42.2 & 44.2 & 0.101 \\
\hline Alcohol use, $\mathrm{n}(\%)$ & $218(90.5)$ & $73(90.1)$ & $10(83.3)$ & 0.722 & $70(74.5)$ & 52 (73.2) & $6(40.0)$ & 0.021 \\
\hline Current smoker, n (\%) & $40(16.6)$ & $11(13.6)$ & $3(16.2)$ & 0.57 & $1(1.1)$ & $0(0.0)$ & $0(0.0)$ & 0.631 \\
\hline \multicolumn{9}{|l|}{ Physical activity, n (\%) } \\
\hline Light intensity & 149 (61.8) & $51(63.0)$ & $9(75.0)$ & 0.652 & $59(62.8)$ & 42 (59.2) & $9(60.0)$ & 0.891 \\
\hline Moderate intensity & $117(48.5)$ & $34(42.0)$ & $4(33.3)$ & 0.666 & $38(40.4)$ & $29(40.8)$ & $1(6.7)$ & 0.034 \\
\hline Vigorous intensity & $103(42.7)$ & $32(39.5)$ & $5(41.7)$ & 0.878 & $21(22.3)$ & $19(26.8)$ & $1(6.7)$ & 0.239 \\
\hline Strength exercises & $73(30.3)$ & $23(28.4)$ & $5(41.7)$ & 0.646 & $16(17.0)$ & $7(9.9)$ & $1(6.7)$ & 0.297 \\
\hline \multicolumn{9}{|l|}{ Medical conditions, $n(\%)$} \\
\hline Hypertension & $6(2.5)$ & $6(7.4)$ & $0(0.0)$ & 0.096 & $2(2.1)$ & $0(0.0)$ & $0(0.0)$ & 0.396 \\
\hline Diabetes mellitus & $1(0.4)$ & $2(2.5)$ & $0(0.0)$ & 0.225 & $1(1.1)$ & $0(0.0)$ & $0(0.0)$ & 0.631 \\
\hline Hyperlipidemia & $5(2.1)$ & $3(3.7)$ & $0(0.0)$ & 0.608 & $1(1.1)$ & $0(0.0)$ & $0(0.0)$ & 0.631 \\
\hline Cardiovascular disease & $1(0.4)$ & $0(0.0)$ & $0(0.0)$ & 0.824 & $1(1.1)$ & $0(0.0)$ & $0(0.0)$ & 0.631 \\
\hline
\end{tabular}

Values are shown as means or numbers (\%).

$\mathrm{ND}$, no depression group (BDI normal); $\mathrm{MiD}$, mild depression group $(10 \leq \mathrm{BDI} \leq 15)$; $\mathrm{MoD}$, moderate depression group $(16 \leq \mathrm{BDI} \leq 23)$.

from a brachial vein; it was immediately centrifuged (3,000 rpm, 15 minutes) to separate the serum and plasma and stored in a freezer at $-75^{\circ} \mathrm{C}$ until the analysis.

\section{Questionnaire}

Current smokers or those within a year of quitting smoking were considered smokers. Non-smokers and those who had quit smoking more than a year ago were considered non-smokers. Alcohol use was classified into having at least one alcoholic beverage per week and having none at all. Participation in physical activities (participation in walking, moderate-intensity physical activity, vigorous-intensity physical activity, and strength exercises within the past seven days) was measured using the International Physical Activity Questionnaires (IPAQ), whose validity and reliability have been verified for use in Korea. The respondents were instructed to indicate participation in vigorous-intensity physical activity or strength exercises if they engaged in at least three 20-minute sessions of such activity weekly, and in moderate-intensity physical activity or walking when they engaged in at least five 30-minute sessions of such activity weekly (IPAQResearch Committee, 2004).

\section{Beck depression inventory (BDI)}

Depressive symptoms were measured using the BDI, which was originally developed by Beck ${ }^{18}$ and adapted by Lee et al. ${ }^{19}$ for use in Korea. The BDI comprises 21 items, and each item comprises four options describing the severity of depressive symptoms. The respondent selects the option that best describes their experience. A score of $0-3$ is given, and a higher total score indicates more severe depression. The cutoffs were as follows: a score of 0-9 was no depression, a score of $10-15$ was mild depression, a score of $16-23$ was moderate depression, and a score of 24-63 was severe depression.

\section{Health-related fitness}

We measured the following health-related fitness components: muscular strength, muscular endurance, flexibility, and cardiorespiratory fitness. First, upper-body muscle strength was measured twice through handgrip strength on the right and left hands using a dynamometer (GRIP-D 501 5101; TAKEI, Co., Japan), and the maximal value was recorded to the nearest $0.1 \mathrm{~kg}$. Muscular endurance was measured through sit-ups, and the number of repetitions performed in one minute was recorded. Flexibility was measured twice through sit and reach, and the highest value was recorded to the nearest $0.1 \mathrm{~cm}$. Finally, cardiorespiratory fitness was measured with a maximal exercise test as per the Bruce protocol. Heart rate (HR) was measured every minute, and blood pressure (BP) and the rate of perceived exertion (RPE) were measured while incre- 
mentally increasing the slope and speed by $2 \%$ in 3-minute intervals from an initial slope of $10 \%$ and speed of $2.7 \mathrm{~km} / \mathrm{h} . \mathrm{VO}_{2} \max$ was calculated using the Bruce equation $\left[\mathrm{VO}_{2} \max =6.70-2.82\right.$ $($ men 1 , women 2$)+0.056($ time of exercise completion $(\mathrm{sec}))]^{20}$

Finally, the total physical fitness score was the sum of the zscores for handgrip, muscular endurance, flexibility, and cardiorespiratory fitness.

\section{Obesity index}

Body weight and percent body fat were measured using the $\mathrm{X}$ Scan Body Composition Analyzer (Jawon Medical Co., Gyeongsangbuk-do, Korea), an automatic body composition analyzer based on biometrical impedance. BMI was calculated using the following equation: $\mathrm{BMI}=\left[\right.$ weight $(\mathrm{kg}) /$ height $\left.\left(\mathrm{m}^{2}\right)\right]$. Waist circumference was measured with the participant standing upright and passing the tapeline parallel to the navel area at the end of expiration. Two measurements were taken, and the mean value was recorded.

\section{Vitamin D}

The active form of blood vitamin D, 1, 25-hydroxyvitamin D [1, $25(\mathrm{OH}) \mathrm{D}]$, has a half-life of four hours and cannot reflect the overall blood vitamin D concentration. Instead, 25-hydroxyvita$\min \mathrm{D}[25(\mathrm{OH}) \mathrm{D}]$ is the best index for the serum vitamin $\mathrm{D}$ level, because most of it binds with a vitamin $\mathrm{D}$ binding protein, which has a half-life of 2 weeks. Hence, we measured the serum vitamin $\mathrm{D}$ level through radioimmunoassay (RIA) using the $25(\mathrm{OH}) \mathrm{D}$ RIA kit (DiaSorin, Stillwater, MN, USA).

\section{Data processing}

Frequency analysis and descriptive statistics were used to analyze the participants' characteristics. Polynomial contrasts of oneway analysis of variance (ANOVA) were used to identify the presence of significant linear trends in physical fitness, blood vitamin D, and obesity indices according to depressive symptoms. The chisquare test $\left(\chi^{2}\right)$ was performed to analyze the differences in smoking, alcohol use, and participation in physical activities according to depressive symptoms. In addition, the associations between lifestyle risk factors and depressive symptoms were analyzed by calculating odds ratios (ORs) using a binomial logistic regression. All data analyses were performed using SPSS ver. 18.0 software (SPSS Inc., Chicago, IL, USA) with the significance set at $\alpha=0.05$.

\section{RESULTS}

We performed separate analyses for women and men to identify how depression status is associated with the obesity index and vitamin D levels. Based on the depression questionnaire results, the participants were classified into no depression (241 men, 94 women, BDI $\leq 9$ points), mild depression ( 81 men, 71 women, $10 \leq$ $\mathrm{BDI} \leq 15$ points), and moderate depression ( 12 men, 15 women, $16 \leq \mathrm{BDI} \leq 23$ points), with no participants showing severe depression ( $24 \leq \mathrm{BDI} \leq 63$ points). Therefore, in this study, we compared the lifestyle risk factors among the no depression, mild depression, and moderate depression groups.

\section{Age and other characteristics according to depressive} symptoms

A total of 514 office workers (334 men, 180 women) who participated in this study were classified into three groups based on their depressive symptoms. Table 1 shows the age and clinical features of the three groups. There were no significant differences in age among the three groups of depression for both men and women. There were no significant intergroup differences in alcohol use for men; however, there was a significant intergroup difference in alcohol use for women $(P=0.021)$. Neither men nor women showed significant intergroup differences in smoking status, hypertension, diabetes, hyperlipidemia, and cardiovascular disease. Furthermore, men did not show significant intergroup differences in any of the physical activity components, whereas women showed a significant intergroup difference in participation in moderate-intensity physical activity $(P=0.034)$.

\section{Health-related fitness according to depressive symptoms}

The comparison of muscular strength, muscular endurance, flexibility, and cardiorespiratory fitness according to depressive symptoms is shown in Table 2. First, both men and women showed a significant linear trend in cardiorespiratory fitness across depressive symptoms; however, no such trend existed in muscular strength, muscular endurance, and flexibility. In other words, the lower the 
Table 2. Comparison of physical fitness according to depressive symptoms of the subject

\begin{tabular}{|c|c|c|c|c|c|c|c|c|}
\hline \multirow[b]{2}{*}{ Variables } & \multicolumn{4}{|c|}{$\operatorname{Men}(n=334)$} & \multicolumn{4}{|c|}{ Women $(n=180)$} \\
\hline & $\begin{array}{c}N D \\
(n=241)\end{array}$ & $\begin{array}{c}\mathrm{MiD} \\
(\mathrm{n}=81)\end{array}$ & $\begin{array}{c}\mathrm{MoD} \\
(\mathrm{n}=12)\end{array}$ & $\begin{array}{c}P \text { value } \\
\text { of linear trend }\end{array}$ & $\begin{array}{c}\mathrm{ND} \\
(\mathrm{n}=94)\end{array}$ & $\begin{array}{c}\mathrm{MiD} \\
(\mathrm{n}=71)\end{array}$ & $\begin{array}{c}M o D \\
(n=15)\end{array}$ & $\begin{array}{c}P \text { value } \\
\text { of linear trend }\end{array}$ \\
\hline Hand grip (kg) & $38.6 \pm 5.7$ & $38.2 \pm 6.3$ & $37.3 \pm 3.8$ & 0.464 & $21.4 \pm 3.9$ & $21.6 \pm 4.1$ & $20.4 \pm 3.0$ & 0.372 \\
\hline Sit-up (frequency/min) & $34.8 \pm 9.3$ & $33.1 \pm 8.4$ & $33.5 \pm 8.1$ & 0.641 & $23.0 \pm 10.6$ & $21.4 \pm 8.9$ & $20.4 \pm 9.8$ & 0.342 \\
\hline Sit-and-reach $(\mathrm{cm})$ & $8.6 \pm 8.5$ & $8.4 \pm 8.2$ & $6.7 \pm 8.4$ & 0.426 & $13.3 \pm 8.3$ & $12.2 \pm 9.3$ & $10.0 \pm 7.8$ & 0.161 \\
\hline Cardiorespiratory fitness $(\mathrm{mL} / \mathrm{kg} / \mathrm{min})$ & $41.6 \pm 5.1$ & $39.7 \pm 4.5$ & $38.2 \pm 4.3$ & 0.02 & $34.7 \pm 3.9$ & $33.0 \pm 3.3$ & $32.4 \pm 4.1$ & 0.025 \\
\hline Total physical fitness (z-score) & $0.2 \pm 2.7$ & $-0.4 \pm 2.8$ & $-1.1 \pm 2.3$ & 0.114 & $0.24 \pm 2.7$ & $0.04 \pm 2.4$ & $-1.3 \pm 2.4$ & 0.038 \\
\hline
\end{tabular}

Values are shown as means \pm SD.

$\mathrm{ND}$, no depression group (BDI normal); $\mathrm{MiD}$, mild depression group (10 $\leq \mathrm{BDI} \leq 15)$; $\mathrm{MoD}$, moderate depression group $(16 \leq \mathrm{BDI} \leq 23)$.

Table 3. Comparison of obesity index according to depressive symptoms of the participants

\begin{tabular}{|c|c|c|c|c|c|c|c|c|}
\hline \multirow[b]{2}{*}{ Variables } & \multicolumn{4}{|c|}{$\operatorname{Men}(n=334)$} & \multicolumn{4}{|c|}{ Women $(n=180)$} \\
\hline & $\begin{array}{c}N D \\
(n=241)\end{array}$ & $\underset{(n=81)}{M i D}$ & $\begin{array}{c}\mathrm{MoD} \\
(n=12)\end{array}$ & $\begin{array}{c}P \text { value } \\
\text { of linear trend }\end{array}$ & $\begin{array}{c}\mathrm{ND} \\
(\mathrm{n}=94)\end{array}$ & $\begin{array}{c}\mathrm{MiD} \\
(n=71)\end{array}$ & $\begin{array}{c}\mathrm{MoD} \\
(n=15)\end{array}$ & $\begin{array}{c}P \text { value } \\
\text { of linear trend }\end{array}$ \\
\hline $\mathrm{BMI}\left(\mathrm{kg} / \mathrm{m}^{2}\right)$ & $24.7 \pm 2.6$ & $24.7 \pm 2.8$ & $25.2 \pm 2.8$ & 0.587 & $23.0 \pm 6.0$ & $22.4 \pm 2.4$ & $21.6 \pm 2.2$ & 0.295 \\
\hline Body fat (\%) & $22.2 \pm 5.0$ & $22.8 \pm 5.6$ & $23.3 \pm 4.7$ & 0.465 & $30.2 \pm 7.1$ & $30.0 \pm 5.9$ & $29.5 \pm 5.1$ & 0.666 \\
\hline WC (cm) & $86.4 \pm 6.8$ & $86.8 \pm 6.8$ & $88.2 \pm 8.7$ & 0.367 & $78.8 \pm 7.1$ & $79.5 \pm 6.4$ & $76.9 \pm 5.4$ & 0.312 \\
\hline
\end{tabular}

Values are shown as means \pm SD.

$\mathrm{BMI}$, body mass index; WC, waist circumference; ND, no depression group (BDI normal); $\mathrm{MiD}$, mild depression group (10 $\leq \mathrm{BDI} \leq 15)$; $\mathrm{MoD}$, moderate depression group (16 $\leq \mathrm{BDI} \leq 23$ ).

Table 4. Comparison of serum vitamin D levels according to depressive symptoms of the participants

\begin{tabular}{|c|c|c|c|c|c|c|c|c|}
\hline \multirow[b]{2}{*}{ Variables } & \multicolumn{4}{|c|}{$\operatorname{Men}(n=334)$} & \multicolumn{4}{|c|}{ Women $(n=180)$} \\
\hline & $\begin{array}{c}N D \\
(n=241)\end{array}$ & $\begin{array}{c}\mathrm{MiD} \\
(\mathrm{n}=81)\end{array}$ & $\begin{array}{c}\mathrm{MoD} \\
(\mathrm{n}=12)\end{array}$ & $\begin{array}{c}P \text { value } \\
\text { of linear trend }\end{array}$ & $\begin{array}{c}N D \\
(n=94)\end{array}$ & $\begin{array}{c}\mathrm{MiD} \\
(n=71)\end{array}$ & $\begin{array}{c}\mathrm{MoD} \\
(n=15)\end{array}$ & $\begin{array}{c}P \text { value } \\
\text { of linear trend }\end{array}$ \\
\hline Vitamin D (ng/mL) & $19.6 \pm 6.7$ & $14.3 \pm 4.5$ & $13.6 \pm 1.8$ & $<0.001$ & $17.9 \pm 8.6$ & $12.2 \pm 3.9$ & $11.8 \pm 3.4$ & $<0.001$ \\
\hline
\end{tabular}

Values shown are means \pm SD.

$\mathrm{ND}$, no depression group (BDI normal); MiD, mild depression group (10 $\leq \mathrm{BDI} \leq 15)$; $\mathrm{MoD}$, moderate depression group $(16 \leq \mathrm{BDI} \leq 23)$.

cardiorespiratory fitness, the worse the depressive symptoms. Further, only women showed a significant linear trend between total physical fitness score (sum of standard scores for each physical fitness component) and depressive symptoms, indicating that the lower the physical fitness, including muscular strength, muscular endurance, flexibility, and cardiorespiratory fitness, the worse the depressive symptoms.

\section{Obesity indices according to depressive symptoms}

The comparison of BMI, body fat percentage, and waist circumference according to depressive symptoms is shown in Table 3. Neither the men nor women had a significant linear trend in obesity across the three depression groups. In other words, male and female office workers' depressive symptoms were not associated with their BMI, body fat percentage, or waist circumference.

\section{Serum vitamin $\mathrm{D}$ concentration according to depressive} symptoms

The comparison of serum vitamin D concentration according to depressive symptoms is shown in Table 4. Both the men and women showed a significant linear trend in blood vitamin $\mathrm{D}$ level according to depressive symptoms. In other words, the lower the male and female office workers' blood vitamin D concentration, the worse the depressive symptoms.

\section{Relative risks for depression predicted by cardiorespiratory fitness and vitamin $\mathrm{D}$ levels}

Among the modifiable lifestyle risk factors, cardiorespiratory fitness and blood vitamin $\mathrm{D}$ level were highly correlated with depressive symptoms. Hence, we classified the participants into the top 25th percentile (high fitness), 50th percentile (middle fitness), and 
Table 5. Odds ratio within 95\% Cl for depressive symptoms according to cardiorespiratory fitness levels and vitamin D level

\begin{tabular}{|c|c|c|c|c|}
\hline \multirow[b]{2}{*}{ Variables } & \multicolumn{2}{|c|}{ Men $(n=334)$} & \multicolumn{2}{|c|}{ Women (n=180) } \\
\hline & $\begin{array}{c}\text { Model } 1 \\
\text { OR (95\% CI) }\end{array}$ & $\begin{array}{c}\text { Model } 2 \\
\text { OR (95\% Cl) }\end{array}$ & $\begin{array}{c}\text { Model } 1 \\
\text { OR (95\% CI) }\end{array}$ & $\begin{array}{c}\text { Model } 2 \\
\text { OR (95\% Cl) }\end{array}$ \\
\hline \multicolumn{5}{|l|}{ Tertile CRF } \\
\hline High Fitness & 1 (reference) & 1 (reference) & 1 (reference) & 1 (reference) \\
\hline Middle Fitness & 1.303 (0.688-2.468) & $1.256(0.647-2.440)$ & 1.252 (0.608-2.577) & $1.190(0.556-2.554)$ \\
\hline Low Fitness & $2.759(1.390-5.476)$ & $2.618(1.216-5.636)$ & 1.564 (0.680-3.595) & $1.596(0.632-4.032)$ \\
\hline \multicolumn{5}{|l|}{ Vitamin D levels } \\
\hline Insufficient or deficient & 1 (reference) & 1 (reference) & 1 (reference) & 1 (reference) \\
\hline Sufficient & $0.108(0.014-0.815)$ & $0.121(0.016-0.920)$ & $0.106(0.012-0.741)$ & $0.114(0.014-0.762)$ \\
\hline
\end{tabular}

Model 1: Unadjusted.

Model 2: Adjusted for age, history of hypertension, diabetes, hyperlipidemia, cardiovascular disease, alcohol intake, current smoking, body mass index, percent body fat, waist circumference.

CRF, cardiorespiratory fitness.

bottom 25th percentile (low fitness) of cardiorespiratory fitness after adjusting for age for each sex (20-64 years, stratified in 10-year intervals), and we also classified the participants based on vitamin D levels into the insufficient $(20 \leq$ vitamin $\mathrm{D}<30 \mathrm{ng} / \mathrm{mL})$ or deficient (vitamin $\mathrm{D}<20 \mathrm{ng} / \mathrm{mL}$ ) group and the sufficient (vitamin $\mathrm{D}$ $\geq 30 \mathrm{ng} / \mathrm{mL}$ ) group to compute participants' relative risk for depressive symptoms (Table 5). First, with regard to the relative risk for depressive symptoms according to cardiorespiratory fitness, the odds ratios for developing depressive symptoms in the male middle fitness and low fitness groups were 1.3 and 2.6, respectively, and those for the female middle fitness and low fitness groups were 1.2 and 1.6, respectively, in model 2. With regard to the relative risks for depressive symptoms according to vitamin $\mathrm{D}$ levels, the vitamin D sufficient group (men and women) had a lower risk of depressive symptoms than did the vitamin $\mathrm{D}$ insufficient or deficient group.

\section{DISCUSSION}

Depressive symptoms are one of the most common mental disorders that affect people's physical and mental health, thereby escalating morbidity, mortality, and suicide as well as posing a grave threat to daily and social living. Identifying the risk factors for depressive symptoms is critical in the aspect of early prediction and management of depression. Thus, this study analyzed the relationships between depressive symptoms and modifiable lifestyle risk factors including physical fitness, vitamin D level, and obesity indices in office workers.
We used the BDI, which has been adapted for use in Korea with confirmed validity and reliability, to measure depressive symptoms. From a total of 514 participants (334 men and 180 women), 335 had no depression (241 men and 94 women), 152 were mildly depressed ( 81 men and 71 women), and 27 were moderately depressed ( 12 men and 15 women), with none of the participants showing severe depression. Thus, we classified the participants into three groups according to depressive symptoms: no depression, mild depression, and moderate depression, and produced the following results.

With regard to the association between physical fitness and depressive symptoms, neither men nor women showed significant differences in muscular strength, muscular endurance, and flexibility according to depressive symptoms; however, they showed a significant difference in cardiorespiratory fitness according to depressive symptoms. Furthermore, when we divided participants into three groups of cardiorespiratory fitness and compared the level of depression adjusting for age, the risk of depression increased with decreasing cardiorespiratory fitness. These results support previous findings and highlight the importance of cardiorespiratory fitness in the prevention and improvement of depressive symptoms. Gerber et al. ${ }^{21}$ reported that the middle or high cardiorespiratory fitness groups were significantly less likely to develop depression than was the low cardiorespiratory fitness group despite exposure to high stress. In a longitudinal study of 10,290 participants, Dishman et al. ${ }^{22}$ reported that prevalence of depression in men and women increased by $2 \%$ and $9.5 \%$, respectively, 
with a reduction of treadmill duration by 1 minute, suggesting that cardiorespiratory fitness plays an important role in the development of depression. In our study, individuals with low cardiorespiratory fitness had a higher relative risk of depressive symptoms than did those with high cardiorespiratory fitness, even after adjusting for age, chronic disease, obesity index, and alcohol/smoking status. In other words, maintenance or improvement of cardiorespiratory fitness is more important than any other measure to prevent and improve depression.

An array of neurotransmitters is involved in the biological mechanism underlying obesity and depression, and it is known that activation of the hypothalamus-pituitary-adrenal axis induces depressive symptoms. In our analysis, obesity indices and depressive symptoms were not associated in either sex. According to a longitudinal study of adults by Ormel et al. ${ }^{23}$, obesity was not independently associated with depression when age, smoking, alcohol use, intensity of physical activity, and presence of chronic disease were controlled for. When Yu et al..$^{24}$ analyzed the association between BMI and depressive symptoms in 20,385 adults aged 18 or older, they found that the overweight group had a higher risk for depressive symptoms than did the normal weight group; however, there is a possibility that the obese group might have a lower risk for depressive symptoms than the normal group. In addition, Onyike et al. ${ }^{25}$ reported that obesity and depressive symptoms are associated only in women. As shown here, despite the volume of previous findings on the association between obesity and depressive symptoms, the results remain heterogeneous with an unclear cause-effect relationship. Such heterogeneity in the results, including ours, is speculated to be due to the differences in the living environments of the participants, instruments for measuring depression, and other extraneous variables.

Meanwhile, our analysis of depressive symptoms and vitamin D levels showed that both men and women had lower depressive symptoms with increasing vitamin D levels. Similarly, in an analysis of the relationships between depression and low vitamin $\mathrm{D}$ levels in individuals aged 15-39 years, Ganji et al. ${ }^{26}$ found an independent relationship between depressive state and low vitamin $\mathrm{D}$ level. Lee et al. ${ }^{27}$ assessed depression in middle-aged European men using the BDI-II and reported an association between vitamin D levels and depressive symptoms. ${ }^{26}$ Further, findings of adults aged 18-65 in the Netherlands also showed a significant association between low vitamin D levels and depressive disorder. In contrast, Milaneschi et al. ${ }^{28}$ did not find a significant relationship between serum vitamin $\mathrm{D}$ concentration and depressive symptoms in 3,916 American adults aged 20 or older, and Zhao et al..$^{29}$ also reported that no significant association existed between vitamin D status and depressive symptoms in 3,262 Chinese elderly. Such contrasting results are presumed to be the result of differences in the participants' characteristics and environments. The participants of our study were office workers, who spend most of their time indoors and have no significant differences among them in terms of the level of physical activity. We speculate that dietary habits ${ }^{30}$ and exposure to sunlight ${ }^{31}$ are the factors that resulted in the differences in vitamin $\mathrm{D}$ levels.

Vitamin D receptors are present in various areas of the brain, including the hippocampus and cingulate cortex, that are involved in the pathophysiology of depression. Biologically, Vitamin D is involved in numerous brain areas and regulates neurotrophic factors, neuroprotection, neuroplasticity, and brain development. ${ }^{32,33}$ As discussed here, the coexistence of modifiable lifestyle risk factors, such as lack of physical activity and vitamin D deficiency, and depressive symptoms is a major topic of interest in Korea and abroad, and depression and depressive symptoms are key physical and mental health problems that affect mortality and quality of life.

Taken together, our findings suggest that ameliorating work environments, such as encouraging appropriate nutritional intake and implementing outdoor physical activity programs to improve physical fitness and ensure adequate levels of vitamin $\mathrm{D}$, should be a priority for the prevention and improvement of depression in office workers.

\section{CONFLICTS OF INTEREST}

We have no conflicts of interest to disclose.

\section{ACKNOWLEDGMENTS}

A National Research Foundation Grant funded by the Korean government (2014R1A1A2056473) supported this work. 


\section{REFERENCES}

1. Kim NJ. Factors associated with stress of employees. Journal of Korean Society for Health Education and Promotion 2007; 24:17-28.

2. Wittchen HU, Jacobi F, Rehm J, Gustavsson A, Svensson M, Jönsson B, et al. The size and burden of mental disorders and other disorders of the brain in Europe 2010. Eur Neuropsychopharmacol 2011;21:655-79.

3. Chesney E, Goodwin GM, Fazel S. Risks of all-cause and suicide mortality in mental disorders: a meta-review. World Psychiatry 2014;13:153-60.

4. National Health Insurance Service. Geriatric depression disorders over the past five years. Seoul: National Health Insurance Service; 2013. [accessed 2015 Nov 18]; Available from: URL: http://www.nhis.or.kr/bbs7/boards/B0039/2951

5. Hickie IB. Preventing depression: a challenge for the Australian community. Med J Aust 2002;177:S85-6.

6. Belmaker RH, Agam G. Major depressive disorder. N Engl J Med 2008;358:55-68.

7. Kendler KS, Gardner CO, Prescott CA. Toward a comprehensive developmental model for major depression in men. Am J Psychiatry 2006;163:115-24.

8. Widome R, Linde JA, Rohde P, Ludman EJ, Jeffery RW, Simon GE. Does the association between depression and smoking vary by body mass index (BMI) category? Prev Med 2009; 49:380-3.

9. Warburton DE, Nicol CW, Bredin SS. Health benefits of physical activity: the evidence. CMAJ 2006;174:801-9.

10. Eyles DW, Burne TH, McGrath JJ. Vitamin D, effects on brain development, adult brain function and the links between low levels of vitamin D and neuropsychiatric disease. Front Neuroendocrinol 2013;34:47-64.

11. Patrick RP, Ames BN. Vitamin D hormone regulates serotonin synthesis. Part 1: relevance for autism. FASEB J 2014;28: 2398-413.

12. Zhang Y, Leung DY, Richers BN, Liu Y, Remigio LK, Riches DW, et al. Vitamin D inhibits monocyte/macrophage proinflammatory cytokine production by targeting MAPK phosphatase-1. J Immunol 2012;188:2127-35.
13. Shaffer JA, Edmondson D, Wasson LT, Falzon L, Homma K, Ezeokoli N, et al. Vitamin D supplementation for depressive symptoms: a systematic review and meta-analysis of randomized controlled trials. Psychosom Med 2014;76:190-6.

14. Anglin RE, Samaan Z, Walter SD, McDonald SD. Vitamin D deficiency and depression in adults: systematic review and meta-analysis. Br J Psychiatry 2013;202:100-7.

15. Dixon JB, Dixon ME, O’Brien PE. Depression in association with severe obesity: changes with weight loss. Arch Intern Med 2003;163:2058-65.

16. Guedes EP, Madeira E, Mafort TT, Madeira M, Moreira RO, Mendonça LM, et al. Body composition and depressive/anxiety symptoms in overweight and obese individuals with metabolic syndrome. Diabetol Metab Syndr 2013;5:82.

17. Kim JH, Suh BS, Kim DI, Yoon KJ, Hong JY, Lee WC, et al. Relationship between symptoms of depression and smoking and obesity in Korean office workers younger than 40 years. Korean J Health Promot 2013;13:25-33.

18. Beck AT. Depression: clinical, experimental, and theoretical aspects. New York: Hoeber Medical Division, Harper \& Row; 1967.

19. Lee MK, Lee YH, Park SH, Sohn CH, Jung YJ, Hong SK, et al. A standardization study of beck depression inventory (I): Korean version (K-BDI): reliability and factor analysis. Korean J Psychopathol 1995;4:77-95.

20. Bruce RA, Kusumi F, Hosmer D. Maximal oxygen intake and nomographic assessment of functional aerobic impairment in cardiovascular disease. Am Heart J 1973;85:546-62.

21. Gerber M, Lindwall M, Lindegård A, Börjesson M, Jonsdottir IH. Cardiorespiratory fitness protects against stress-related symptoms of burnout and depression. Patient Educ Couns 2013;93:146-52.

22. Dishman RK, Sui X, Church TS, Kline CE, Youngstedt SD, Blair SN. Decline in cardiorespiratory fitness and odds of incident sleep complaints. Med Sci Sports Exerc 2015;47:960-6.

23. Ormel J, VonKorff M, Ustun TB, Pini S, Korten A, Oldehinkel T. Common mental disorders and disability across cultures. Results from the WHO Collaborative Study on Psychological Problems in General Health Care. JAMA 1994;272: 1741-8. 


\section{Yu NW, Chen CY, Liu CY, Chau YL, Chang CM. Association} of body mass index and depressive symptoms in a Chinese community population: results from the Health Promotion Knowledge, Attitudes, and Performance Survey in Taiwan. Chang Gung Med J 2011;34:620-7.

25. Onyike CU, Crum RM, Lee HB, Lyketsos CG, Eaton WW. Is obesity associated with major depression? Results from the Third National Health and Nutrition Examination Survey. Am J Epidemiol 2003;158:1139-47.

26. Ganji V, Milone C, Cody MM, McCarty F, Wang YT. Serum vitamin $\mathrm{D}$ concentrations are related to depression in young adult US population: the Third National Health and Nutrition Examination Survey. Int Arch Med 2010;3:29.

27.Lee DM, Tajar A, O’Neill TW, O’Connor DB, Bartfai G, Boonen $\mathrm{S}$, et al. Lower vitamin $\mathrm{D}$ levels are associated with depression among community-dwelling European men. J Psychopharmacol 2011;25:1320-8.

28. Milaneschi Y, Hoogendijk W, Lips P, Heijboer AC, Schoevers R, van Hemert AM, et al. The association between low vitamin D and depressive disorders. Mol Psychiatry 2014;19:444-51.

29. Zhao G, Ford ES, Li C, Balluz LS. No associations between serum concentrations of 25-hydroxyvitamin $\mathrm{D}$ and parathyroid hormone and depression among US adults. Br J Nutr 2010;104:1696-702.

30. Pan A, Lu L, Franco OH, Yu Z, Li H, Lin X. Association between depressive symptoms and 25-hydroxyvitamin D in middle-aged and elderly Chinese. J Affect Disord 2009;118: 240-3.

31. Lips P. Vitamin D physiology. Prog Biophys Mol Biol 2006; 92:4-8.

32. Rosen CJ. Clinical practice. Vitamin D insufficiency. N Engl J Med 2011;364:248-54.

33. Eyles DW, Smith S, Kinobe R, Hewison M, McGrath JJ. Distribution of the vitamin $\mathrm{D}$ receptor and 1 alpha-hydroxylase in human brain. J Chem Neuroanat 2005;29:21-30. 